\title{
EAS Publications Series
}

Volume 1 AGN in their Cosmic Environment (JENAM'99)

September 7-9, $1999 \bullet \mathbf{3 0} €$

Volume 2 GAIA: A European Space Project

May 14-18, 2001•60€

Volume 3 Star Formation and the Physics of Young Stars

(Summer School on Stellar Physics X)

September 18-22, 2000 • $40 €$

Volume 4 Infrared and Submillimeter Space Astronomy

June 11-13, 2001•65 €

Volume 5 Radiative Transfer and Hydrodynamics in Astrophysics (GRETA)

November 28, 2001•25€

Volume 6 Observing with the VLT Interferometer (EuroWinter School)

February 3-8, 2002 • $47 €$

Volume 7 Final Stages of Stellar Evolution (Summer School on Stellar Physics XI)

September 16-21, 2001・52 €

Volume 8 Astronomy with High Contrast Imaging

May 13-16, 2002 • $56 €$

Volume 9 Magnetism and Activity of the Sun and Stars

September 17-21, 2002 • $56 €$

Volume 10 Galactic \& Stellar Dynamics (JENAM 2002)

September 3-6, 2002 • $36 €$

Volume 11 The Future Astronuclear Physics

August 20-22, $2003 \bullet \mathbf{4 7 . 5 0} €$

Volume 12 Astronomy with High Contrast Imaging II

October 6-10, 2003• $\mathbf{5 6} €$

Volume 13 Evolution of Massive Stars, Mass Loss and Winds

(Summer School on Stellar Physics XII-XIII)

October 13-18, 2002 and October 6-10, 2003 • $50 €$

Volume 14 Dome C: Astronomy and Astrophysics Meeting

June 28-30, 2004 • $63 €$

Volume 15 Radio Astronomy from Karl Jansky to Microjansky (JENAM 2003)

August 27-30, 2003 • $72 €$ 
Volume 16 Teaching and Communicating Astronomy (JENAM 2004)

September 13-17, 2004 • $44 €$

Volume 17 Element Stratification in Stars: 40 Years of Atomic Diffusion

Meeting in Honour of Georges Michaud

June $6-10,2005 \bullet 60 €$

Volume 18 Radiative Transfer and Applications to Very Large Telescopes (GRETA)

May 11-13, 2005• $47 €$

Volume 19 Stars and Nuclei: A Tribute to Manuel Forestini

March 4-5, 2004 • $36 €$

Volume 20 Mass Profiles and Shapes of Cosmological Structures (IAP 2005)

July 4-9, 2005• $47 €$

Volume 21 Stellar Fluid Dynamics and Numerical Simulations:

From the Sun to Neutron Stars

September, 2004 and May, 2005 • $55 €$

Volume 22 Astronomy with High Contrast Imaging III: Instrumental Techniques, Modeling and data Processing

May 16-19, 2005• $55 €$

Volume 23 Sky Polarisation at Far-Infrared to Radio Wavelengths: The Galactic Screen before the Cosmic Microwave Background

September 12-15, 2005• $39 €$

Volume 24 CRAL-2006. Chemodynamics: From First Starts to Local Galaxies July 10-14, 2006• $47 €$

Volume $25 \quad 1^{\text {st }}$ ARENA Conference on "Large Astronomical Infrastructures at CONCORDIA, prospects and constraints for Antarctic Optical/IR

Astronomy"

October 16-19, $2006 \bullet 47 €$

Volume 26 Stellar Evolution and Seismic Tools for Asteroseismology

November 20-23, 2006• $32 €$

Volume 27 The Third European Summer School on Experimental Nuclear

Astrophysics

October 2-9, 2005• $39 €$

Volume 28 Perspectives in Radiative Transfer and Interferometry

May 14-16, 2007 • $25 €$

Volume 29 Tidal Effects in stars, Planets and Disks

September 5-9, 2005 • $47 €$ 
Volume 30 Spanish Relativity Meeting - Encuentros Relativistas Españoles ERE2007

September $10-14,2007 \bullet 63 €$

Volume $31 \quad$ Far-Infrared Workshop 2007

November 5-7, 2007• $39 €$

Volume 32 Stellar Nucleosynthesis 50 Years after B ${ }^{2} \mathrm{FH}$

December 4-8, 2006 • $63 €$

Volume $332^{\text {nd }}$ ARENA Conference on "The Astrophysical Science Cases at Dome C" September 17-21, 2007• $55 €$

Volume 34 Astronomy in the Submillimeter and Far Infrared Domains with the Herschel Space Observatory

April 23-May 4, 2007• $47 €$

Volume 35 Interstellar Dust from Astronomical Observations to Fundamental Studies May $1^{s t}-5,2006 \bullet 47 €$

Volume 36 Dark Energy and Dark Matter

and Theories

July $7-11,2008 \bullet 55 €$

Volume 37 Astrophysics Detector Workshop 2008

November 17-20, 2008 • $63 €$

Volume 38 Nonlinear Pulsations and Hydrodynamics of Cepheids

July $9-13,2007 \cdot 32 €$

Volume 39 Stellar Magnetism

September 24-28, 2007 • $39 €$

Volume $40 \quad 3^{\text {rd }}$ ARENA Conference on "An Astronomical Observatory at CONCORDIA (Dome C, Antarctica)"

May 11-15, 2009• $87 €$

Volume 41 Physics and Astrophysics of Planetary Systems

February 18-29, 2008 • $95 €$

Volume 42 Extrasolar Planets in Multi-Body Systems: Theory and Observations August 25-29, 2008 • $79 €$

Volume 43 Non-LTE Line Formation for Trace Elements in Stellar Atmospheres July 30 - August 03, 2007• $43 €$

Volume 44 JENAM 2008: Grand Challenges in Computational Astrophysics September 8-11, 2008 • $26 €$

Volume 45 GAIA: At the Frontiers of Astrometry

June $7-11,2010 \bullet 78 €$ 
Volume 46 PAHs and the Universe: A Symposium to Celebrate the $25^{\text {th }}$ Anniversary of the PAH Hypothesis

May 31-June 04, 2010•69€

Volume 47 Astronomical Spectrography for Amateurs

May 06-11, 2003 • $35 €$

Volume 48 CRAL-2010: A Universe of Dwarf Galaxies June 14-18, 2010 • 87€

Volume 49 Scientific Writing for Young Astronomers - Part 1 2008-2009• $35 €$

Volume 50 Scientific Writing for Young Astronomers - Part 2 $2008-2009 \bullet 60 €$

Volume 51 Star Formation in the Local Universe - EES2010 September 16 - October 1, $2010 \bullet \mathbf{5 1 . 7 5} €$

Volume 52 Conditions and Impact of Star Formation - New results with Herschel and Beyond

September 19-24, $2010 \bullet 60 €$

Volume 53 CYGNUS 2011

June $8-10,2011 \bullet 35 €$ 